\title{
BC cuts cardiac wait-list by one-third
}

An initiative that successfully cut BC's cardiac waiting list by onethird during a 10-month period will continue for another year, said an official with the Provincial Health Services Authority.

The cardiac waiting list was reduced through a combination of $\$ 3.4$ million in extra funding between 2003 and 2004 and more effective recruitment of staff - especially critical care nurses - by facilities, said Dr. Robert Halpenny, executive director of Cardiac Services with the provincial agency.

The province announced Aug. 17 that it is spending an$\approx$ other $\$ 5$ million on improving F cardiac care.

In June 2003, 623 people were waiting for surgery, but by April 2004 that number had dropped to 409 . A total of 3253 cardiac care cases were funded in BC in 2003. Median waiting times were also reduced from 18 weeks last fall to 14.9 weeks by April.

A panel of cardiac specialists had earlier advised the authority that open-heart surgery was the priority. As a result, $\$ 2$ million of the new funds was spent on 144 patients who had openheart surgeries. The remainder was spent on implantable cardioverter defibrillators for 29 people, a relatively new type of drug-eluting stent, and ventricular-assistance devices for patients on the waiting list at St. Paul's Hospital in Vancouver.

"Cardiovascular disease is the leading cause of death in British Columbia, and research shows rates will increase over the next 20 years," noted Health Services Minister Colin Hansen.

"The wait-list developed over time, partly because of an inability to find staff," said
Halpenny. The staffing shortages meant facilities couldn't achieve their targets in cardiac care, he said, which eventually compounded the problem.

Extra provincial funding was key to looking after the extra patients last year, said Halpenny. But what made the difference in the ability to actually perform surgeries was an easing in the shortage of critical care nurses.

"The important thing is that we're going to continue to fund over the next year at an increased rate," said Halpenny.

The additional $\$ 5$ million this year is expected to boost the number of open-heart surgeries by $5 \%$, thus reducing waiting times to a maximum of 3 months. About \$2 million will be spent on medical devices for high-risk patients. - Deborah fones, Vancouver 